\title{
Roy Adaptation Model to Promote Physical Activity and Quality of Life in Diabetics: A Review
}

\author{
Iram Majeed ${ }^{1 *}$, Sana Sehar ${ }^{2}$, Muhammad Afzal $^{3}$, Syed Amir Gilani ${ }^{4}$ \\ ${ }^{1}$ Lecturer, Lahore School of Nursing, The University of Lahore, Pakistan \\ ${ }^{2}$ Assistant Professor, Lahore School of Nursing, The University of Lahore, Pakistan. \\ ${ }^{3}$ Associate Professor, Lahore School of Nursing, The University of Lahore, Pakistan \\ ${ }^{4}$ Dean, Faculty of Allied Health Sciences, The University of Lahore, Pakistan
}

DOI: $10.36348 /$ SJNHC.2019.v02i09.004

| Received: 16.08.2019 | Accepted: 01.09.2019| Published: 23.09.2019

*Corresponding author: Iram Majeed

\section{Abstract}

Roy' adaptation model helps to adapt healthy behaviors in diseases which are impossible to cure. According to this model, care should be aimed in enhancing adaptive capabilities and increasing the coping response of individuals to deal with stressor. Roy's adaptation model is widely used due to its simplicity and accessibility for improving quality of life. Roy 'adaptation model is important to promote individuals' adaptation in changing health care demands, thus improving adjustment, quality of life and dying with dignity Roy' adaptation model based care plan is a non-invasive non medicated and cost efficient way to limit physical and psychological issues of patients with chronic diseases. Purpose of this paper is to evaluate different articles which used Roy adaptation model for care of chronic illnesses. Nine different studies are included in this paper to evaluate the efficacy of Roy adaptation model.

Keywords: Physical Activity, Diabetics, Roy's adaptation model.

Copyright @ 2019: This is an open-access article distributed under the terms of the Creative Commons Attribution license which permits unrestricted
use, distribution, and reproduction in any medium for non-commercial use (NonCommercial, or CC-BY-NC) provided the original author and source
are credited.
are credited.

\section{OVERVIEW OF THEORY}

Adaptation model states that a person is a biopsycho-social being who is in constant interaction with a changing environment [1]. In order to respond positively to environmental changes, a person need to adopt it. A person's adaptation is a function of the stimulus he is exposed [2]. The person's adaptation level is such that it comprises a zone indicating the range of stimulation that lead to a positive response [3]. According to Roy "health is not freedom from the inevitability of death, disease, unhappiness, and stress, but the ability to cope with them in competent way to improve quality of life [4].

\section{LITERATURE REVIEW}

Study was conducted to assess the effect of psychological adaptation on Quality of life among diabetes patients. Findings revealed that Roy based interventions significantly affected the physiological and psychological aspects of diabetic patients. Furthermore, interventions based on Roy model with holistic and interdisciplinary approach proved helpful for patients' adaptation and significantly reduced the maladaptive behavior in self-concept $(\mathrm{p}=0 / 000)$ and interdependence mode in diabetics. Quality of life was enhanced significantly on adapting caring behaviors based on Roy model [5].

Studies depict that significant association exists between social support and QoL among diabetics [6]. Adaptation model affects quality of life dimensions to control diabetes related complications. Enhanced coping modalities overcome maladaptation and improve the QoL. Findings reveal the positive effects of RAM on quality of life among diabetics. Roy' model based interventions showed significant impact of social support on quality of life among diabetics and resulted in positive patient' outcomes [7].

Other dimensions related to Roy' physiological mode i.e., exercise and mobility are directly linked with improved quality of life in diabetics by preventing insulin resistance [8]. Research implicated the effects of physical activity for preventing complication in diabetes. Routinely planned exercises to enhance physical activity play a crucial role in the management of diabetes. There is a need to incorporate specific exercise programs in health care system to prevent risk of complications among diabetics [9]. 
Furthermore, the aspect of self-concept by applying caring plan based on Roy's adaptation model showed significant impact for advancing the physical well-being of diabetics with statistically significant results $(\mathrm{P}<0.001)$. Therefore, it's proposed to health care providers to focus on adaptive capabilities with healthy practices as a basic element for promoting the physical well-being of the patients. The findings of current research demonstrated that RAM based caring interventions positively affect physical wellbeing [10].

Maslakpak, Maghsoodi, and Sheikhi [11] conducted a study on the level of HbA1c and the maladaptive practices in diabetics. Roy adaptation model based care improved the maladaptive practices of patient in physical $(\mathrm{p}=0 / 000)$ and interdependence mode in the intervention group. Level of $\mathrm{HbA1c}$ was diminished significantly $(p=0 / 000)$ after the interventions. Control group was unable to show any adaptive capabilities. RAM proved helpful for the care of diabetics by utilizing holistic and interdisciplinary approach for physiological adaptation [12].

Interventions based on RAM affect the quality of life regarding patients' adaptation in physical and self-concept mode. Roy based strategies enhance patients' perception regarding illness, develop behaviors necessitating self-care activities and provided adaptive capabilities to deal with chronic illnesses [13]. Roy' model based interventions showed significant effects in physiological and self-concept modes with improved quality of life $(\mathrm{P}=0.01$ and $\mathrm{P}=0.03$ respectively). Role function mode was also significantly related $(\mathrm{P}=0.04)$. Furthermore, findings concluded that Roy based interventions have significant role to improve patients' quality of life in physical, selfconcept and role function mode [14].

Farsi, and Azarmi conducted a study on relationship between educational strategies based on Roy's adaptation model and diabetics' adaptation in physical and role function modes. Findings demonstrated that Roy's adaptation model based educational strategies promoted the adaptation level in basic life functioning and role performance modes in patients with diabetes $(\mathrm{P}=0.001)$. Intervention group showed statistically significant difference in physiologic $(\mathrm{P}=0.0001)$ and role function modes $(\mathrm{P}=0.004)$. Interventions based on Roy's adaptation model are essential for improving the adaptation of diabetics [15].

The study conducted to examine the effect of Roy adaptation model on quality of life showed significant differences in the physical, emotional and total dimensions of quality of life $(p<0.001)$ in the intervention group. In addition, there were significant differences in interpersonal support after intervention $(\mathrm{p}<.001)$. Result demonstrated that teaching program based on RAM was effective in improving the quality of life and interpersonal support for patients [16].
Manaviat, Rashidi, and Mohammadi conducted a study on physiological adaptation in patients affected with diabetes. Significant difference founded in mean score of adaptation in physiological measurement in the investigation group $(\mathrm{P}<0.001)$ contrasted with before intervention. Results of the study showed that RAM based care plan result in an increase physiological adaptation in patients with diabetes [17].

\section{CONCLUSION}

This paper addressed and reviewed the application of the ROY adaptation theory. The RAM conceptual framework was used to guide and direct the clinical setting and it appears that concepts of RAM can be easily implemented to identify the adaptive strategies of patients. The RAM is an effective guide for clinical practice. In above cited 9 studies it was obvious that RAM is really a pillar of clinical practice and if applied effectively it helps to cope chronic illnesses.

\section{RECOMMENDATION}

Based on study it is essential to initiate such a model based care in routine clinical practice. There is a need initiate a nationwide standard chronic care model like Roy adaptation model that follows strictly guidelines as it has the potential to improve care and reduce costs. Government and policy makers should take steps to enhance physical fitness and quality of life in patients with chronic illnesses like diabetes with the help of theoretical dimensions.

\section{REFERENCES}

1. Roy, C., \& Andrews, H. A. (1999). The Roy adaptation model. Stamford, CT: Appleton \& Lange.

2. Porojan, M., Poanta, L., \& Dumitrascu, D. L. (2012). Assessing health related quality of life in diabetic patients. Rom J Intern Med, 50(1), 27-31.

3. Sarfo, J. O., Cudjoe, J., Fosu, A., \& Schlatter, M. C. (2015). Health-related quality of life indicators in Ghana: comparing Type 2 diabetic and control groups. Journal of Advocacy, Research and Education, 3(2), 135-145.

4. Roy, C. (1980). The Roy adaptation model.

5. Borzou, R., Khan Mohammadi, S., Falahinia, G. H., Mousavi, S., \& Khalili, Z. (2015). Effects of roy's adaptation model in nursing practice on the quality of life in patients with type II diabetes. Journal of Nursing and Midwifery Sciences, 2(4), 1-7.

6. Andrews, H. A., \& Roy, C. (1991). The Roy adaptation model. Appleton \& Lange.

7. Alipour, M., Salehi, I., \& Soufi, F. G. (2012). Effect of exercise on diabetes-induced oxidative stress in the rat hippocampus. Iranian red crescent medical journal, 14(4), 222.

8. Roy, S. C. (1988). An explication of the philosophical assumptions of the Roy adaptation model. Nursing science quarterly, 1(1), 26-34. 
9. Saremi, A. (2011). Sporting exercises and diabetes mellitus type 2: a review on evidences.

10. Maghsoodi, E., Naseri, O., \& Hemmati Maslak Pak, M. (2016). The Effect of Care Plan Application Based on Roy's Adaptation Model on The Spiritual Well-Being of Elderly People in Urmia Nursing Homes. International Journal of Medical Research \& Health Sciences, 5(11), 408414.

11. Hemmati Maslak Pak, M., Sheikhi, S., \& Maghsoodi, E. (2015). The effects of a care program based on the Roy adaptation model on nursing home residents' quality of life. Mod Care Journal, 12(4), 1-6.

12. Colberg, S. R., Sigal, R. J., Fernhall, B., Regensteiner, J. G., Blissmer, B. J., Rubin, R. R., ... \& Braun, B. (2010). Exercise and type 2 diabetes: the American College of Sports Medicine and the American Diabetes Association: joint position statement. Diabetes care, 33(12), e147-e167.
13. Gåfvels, C., \& Wändell, P. E. (2006). Coping strategies in men and women with type 2 diabetes in Swedish primary care. Diabetes research and clinical practice, 71(3), 280-289.

14. Roy, C. (2011). Extending the Roy adaptation model to meet changing global needs. Nursing Science Quarterly, 24(4), 345-351.

15. Farsi, Z., \& Azarmi, S. (2016). Effect of Roy's adaptation model-guided education on coping strategies of the veterans with lower extremities amputation: A double-blind randomized controlled clinical trial. International journal of community based nursing and midwifery, 4(2), 127.

16. Muslu, L., \& Ardahan, M. (2018). Diabetes Mellitus' ta Yaşam Tarzı Değişimi için Motivasyonel Görüşme Tekniği. Psikiyatride Güncel Yaklaşımlar, 10(3), 346-357.

17. Manaviat, M. R., Rashidi, M., \& Mohammadi, S. M. (2009). Wolfram Syndrome presenting with optic atrophy and diabetes mellitus: two case reports. Cases Journal, 2(1), 9355. 